\title{
Relationship between Yield stress and yield Strength on Various Grade of steel Being Hot rolled
}

\author{
O.O. Tairu ${ }^{3}$ and P. O. Aiyedun ${ }^{1}$, O.T. Tairu ${ }^{2}$ \\ ${ }^{1}$ Department of Mechanical Engineering, University of Ibadan, \\ ${ }^{2}$ Department of Mechanical Engineering, University of Ibadan \\ ${ }^{3}$ Department of Mechanical Engineering, Yaba College of Technology
}

\begin{abstract}
Stress is ability of materials to resist failure. The relationship between yield strength and yield stress of various grade of steel being hot rolled is necessary to predetermine the failure of engineering materials.The Torsional tests obtained by previous researchers for temperature range of $600^{\circ} \mathrm{C}$ to $1201^{\circ} \mathrm{C}$ and Strain rate of 0.0001 to $5.0 \mathrm{sec}^{-1}$ were analyzed with the aim of obtaining the relationship necessary to describe the yield stress and yield strength of each material as a function of the deformation variables (Strain rate and temperature). The Stress-Strain data provided by the data were transformed to generate Stress-Strain equations, which were consequently used to determine the yield Stress and yield strength, likewise the relationship between the yield stress and yield strength due to load and torque for all the materials analyzed.
\end{abstract}

\section{Introduction}

Stress is a measure of internal reaction between elementary particles of a material in resisting separation, compaction, or sliding that tends to be induced by external forces (Aiyedun et al, 2010).Strength is defined as the ability to resist failure under the action of an applied stress. The yield point of a material in engineering and material science is the Stress at which a material begins to deform plastically.The strength of a material depends on the material composition, the thermo mechanical history before working (Roberts and Ahlblom, 1978). Prior to the yield point the material will deform elastically and will return to its original shape when the applied stress is removed. Once the yield point is passed, some fraction of the deformation will be permanent and non-reversible.

Yield strength is the stress accompany a specific permanent plastic strain which is considered as not having impaired useful elastic behavior and it represent the practical elastic strength for material having a gradual knee in the stress-strain curve. Yield Stress is the stress at which flow occurs in a material and it dependent on both the rate of deformation (strain rate) and, more significantly, the temperature at which the deformation occurs. Yield stress of a material is influenced by two factors; factors unrelated to the deformation process such as, chemical composition, metallurgical structure phases, grain size, segregation, prior strain history, then, the factors related to the deformation process such as; temperature of deformation, strain and strain rate (Dieter, 1986). During the process of hot working, the knowledge of temperature is very vital in estimating yield strength and yield stress.

Alder and Philips in (1954-55) found that the relationship between yield stress and strain rate (at constant temperature)

$$
\sigma_{y}=C(\dot{\epsilon})^{m}
$$

Where $\mathrm{C}$ is a constant and $\mathrm{m}$ is the strain rate sensitivity. The latter generally increases with temperature, and materials where $\mathrm{m}$ reaches a value greater than $\sim 0.5$ tend to exhibit super plastic behavior.Later, more complex equations were proposed that simultaneously dealt with both temperature and strain rate:

$$
\sigma_{y}=\frac{1}{\alpha} \sinh ^{-1}\left[\frac{Z}{A}\right]^{(1 / n)}
$$

Where $\alpha$ and $\mathrm{A}$ are constants and $\mathrm{Z}$ is the temperature-compensated strain-rate - often described by the Zener-Hollomon parameter:Since both yield strength and yield stress are strongly temperature, strain and strain rate dependent, the stress-strain behavior of the material can be estimate using Zener-Hollomon relationship.

$$
Z=(\dot{\epsilon}) \exp \left(\frac{Q_{H W}}{R T}\right)
$$

Where $\mathrm{Q}_{\mathrm{HW}}$ is the activation energy for hot deformation and $\mathrm{T}$ is the absolute temperature. 
According to Aiyedun (1999), the yield stress of a material under torsional load is $\overrightarrow{\sigma_{G}}=\frac{1}{\epsilon_{m}} \int_{0}^{\epsilon} \sigma d \epsilon$

Similarly, the yield stress due to torque on the material

$$
\overrightarrow{\sigma_{T}}=1 / \varepsilon_{m}^{2} \int_{0}^{\varepsilon} \sigma \varepsilon d \varepsilon
$$

Similarly according to Aiyedun (1999), the yield strength due to load

$$
\overrightarrow{\sigma_{\mathrm{g}}}=\frac{\frac{1}{3}\left(\sigma_{0} * \varepsilon_{0}+\sigma_{1} * \varepsilon_{1}+\sigma_{2} * \varepsilon_{2}\right)}{\varepsilon_{\mathrm{p}}} \ldots
$$

The yield strength due to torque $\left(\overrightarrow{\sigma_{t}}\right)$

$$
\overrightarrow{\Sigma_{\mathrm{t}}}=\frac{\frac{1}{3}\left(\sigma_{0} \varepsilon_{0} * \varepsilon_{0}+\sigma_{1} \varepsilon_{1} * \varepsilon_{1}+\sigma_{2} \varepsilon_{2} * \varepsilon_{2}\right)}{\varepsilon_{\mathrm{p}}^{2}}
$$

The main hot working tests used in determine the resistance of a material to deformation are; scaled down tests (such as rolling, extrusion, forging etc) and mechanical tests (such as tension, compression, torsion and bending). Torsion testing under hot rolling in which a twisting is applied to a material has been accepted worldwide, at strain rates of $10^{-3}$ to $10^{2} \mathrm{~s}^{-1}$, measurement of flow stress are obtained (Aiyedun, 1999).

\section{Methodology}

Hot torsion testing data for seven different grades of stainless steels for strain rates of $10^{-3}$ to $1.5 \mathrm{~s}^{-1}$ and temperature range of $600^{\circ} \mathrm{C}$ to $1200^{\circ} \mathrm{C}$ were used to calculate the yield strength and yield stress due to load and torque for each of the steel. The calculated yield strength and yield stress of each material were used to establish a relationship and which were then translated into a linear equations using a computer programming. The relationship can be used to predict the rolling load and torque for the material.

Under the stress-strain behavior of steel, for SS316, increasing strain, $\varepsilon$, the equivalent stress increases during the initial work hardening stage to a maximum value and then falls to a steady-state flow stress. The stress at a given strain, and the strain to the peak stress, $\varepsilon_{\rho}$, increase with increasing strain rate and decreasing temperature. Zener-Hollomon (1944) proposed an equation combining the simultaneous effect of strain rate and temperature on yield stress.

$$
\sigma=f\left(\dot{\varepsilon} \exp \frac{Q}{R T}\right)
$$

Where $\dot{\varepsilon}=$ Strain rate, $\mathrm{Q}=$ Experimental activation energy for deformation associated with the temperature dependence of the flow stress, $\mathrm{R}=$ Gas constant and $\mathrm{T}=$ Absolute temperature. Algebraic equations relating peak stress, peak strain and stress to strain of 0.1/0.15 were obtained from the torsional tests analyzed

$$
\begin{gathered}
\sigma_{p}=A_{1}+B_{1} * \log _{10} Z \\
\log _{10} Z \ldots \ldots \ldots \ldots \ldots \ldots \ldots \\
\epsilon_{p}=B_{3} * Z
\end{gathered}
$$$$
\text { (9) } \sigma_{0.1 / 0.15}=A_{2}+B_{2} *
$$

Where $\mathrm{A}_{(1-3)}$ is the intercepts and $\mathrm{B}(1-3)$ the slopes.

With varying values of $\log _{10} \mathrm{Z}$ and the equations, the actual values of $\sigma_{p}, \epsilon_{p}$ and $\sigma_{0.1 / 0.15}$

Considering three division of the material profile, the true yield stress due to load on the material

$$
\overrightarrow{\sigma_{\mathrm{G}}}=\frac{1}{\varepsilon_{m}} \int_{0}^{\varepsilon} \sigma d \varepsilon
$$

Where $\int_{0}^{\varepsilon} \sigma d \varepsilon=1 / 2\left(\sigma_{1}+\sigma_{2}\right)\left(\varepsilon_{2}-\varepsilon_{1}\right)+1 / 2\left(\sigma_{2}+\sigma_{3}\right)\left(\varepsilon_{3}-\varepsilon_{2}\right)+. .+1 / 2\left(\sigma_{n-1}+\sigma_{n}\right)\left(\varepsilon_{n}-\varepsilon_{n-1}\right)$

$$
\overrightarrow{\Sigma_{\mathrm{G}}}=\frac{\frac{1}{2}\left(\sigma_{0}+\sigma_{1}\right)\left(\varepsilon_{1}-\varepsilon_{0}\right)+\frac{1}{2}\left(\sigma_{1}+\sigma_{2}\right)\left(\varepsilon_{2}-\varepsilon_{1}\right)}{\epsilon_{\mathrm{P}}}
$$

$\epsilon_{0}=0.0, \epsilon_{1}=0.1, \epsilon_{2}=0.15$

$\sigma_{0}=0.53 \sigma_{\mathrm{p}}($ for the strain at 0.1$), \sigma_{0}=0.47 \sigma_{P}($ for the strain at 0.15$), \sigma_{1}=\sigma_{0.1}$

$\sigma_{2}=0.75 \sigma_{P}\left(\right.$ If $\left.\epsilon_{p}<0.2\right), \sigma_{2}=0.9 \sigma_{P}$ (If $\left.0.2<\epsilon_{p}<0.4\right), \sigma_{2}=\sigma_{P}($ If

$\left.0.4<\epsilon_{p}<1.6\right) \sigma_{2}=1.1 \sigma_{\mathrm{p}}\left(\right.$ if $\left.\epsilon_{p}>1.6\right)$

Similarly, the yield stress due to torque on the material

$$
\varepsilon_{m}=\varepsilon_{p}
$$

$$
\overrightarrow{\sigma_{T}}=1 / \varepsilon_{m} \int_{0}^{\varepsilon} \sigma \varepsilon d \varepsilon
$$


Where

$\int_{0}^{\varepsilon} \sigma \varepsilon d \varepsilon=\frac{1}{2}\left(\sigma_{1} \varepsilon_{1}+\sigma_{2} \varepsilon_{2}\right)\left(\varepsilon_{2}-\varepsilon_{1}\right)+\cdots \ldots \ldots .+\frac{1}{2}\left(\sigma_{n-1} \varepsilon_{n-1}+\sigma_{n} \varepsilon_{n}\right)\left(\varepsilon_{n}-\varepsilon_{n-1}\right)$

$\overrightarrow{\sigma_{\mathrm{T}}}=\frac{\frac{1}{2}\left(\sigma_{0} \varepsilon_{0}+\sigma_{1} \varepsilon_{1}\right)\left(\varepsilon_{1}-\varepsilon_{0}\right)+\frac{1}{2}\left(\sigma_{1} \varepsilon_{1}+\sigma_{2} \varepsilon_{2}\right)\left(\varepsilon_{2}-\varepsilon_{1}\right)}{\varepsilon_{\mathrm{P}}^{2}}$

Where the symbols are as above

The yield strength for the whole profile of the material according to Aiyedun (1999)

The yield strength due to Load $\left(\overrightarrow{\sigma_{g}}\right)$

$$
\overrightarrow{\sigma_{\mathrm{g}}}=\frac{\frac{1}{3}\left(\sigma_{0} * \varepsilon_{0}+\sigma_{1} * \varepsilon_{1}+\sigma_{2} * \varepsilon_{2}\right)}{\varepsilon_{\mathrm{p}}}
$$

The yield strength due to torque $\left(\overrightarrow{\sigma_{t}}\right)$

$$
\overrightarrow{\sigma_{\mathrm{t}}}=\frac{\frac{1}{3}\left(\sigma_{0} \varepsilon_{0} * \varepsilon_{0}+\sigma_{1} \varepsilon_{1} * \varepsilon_{1}+\sigma_{2} \varepsilon_{2} * \varepsilon_{2}\right)}{\varepsilon_{\mathrm{p}}{ }^{2}}
$$

Where the symbols are as above

Using regression line equation, relationship between the yield stress and the yield strength is established as thus. Due to load

$$
\overrightarrow{\sigma_{\mathrm{g}}}=\mathrm{A}_{4}+\mathrm{B}_{4} \overrightarrow{\sigma_{\mathrm{G}}}
$$

Due to torque

$$
\overrightarrow{\sigma_{t}}=A_{4}+B_{4} \overrightarrow{\sigma_{T}}
$$

\section{Stress-strain equations}

\section{Results And Discussion}

The torsion tests experimental data for different materials over a range of temperature from $600^{\circ} \mathrm{C}$ to $1201{ }^{0} \mathrm{C}$ and at strain rates from 0.0001 to $5.0 \mathrm{sec}^{-1}$ of seven grades of stainless steel were analyzed. The dependence of the peak stress, stress to strain at $0.1 / 0.15$ and peak strain on the Zener-Hollomon parameter are shown in fig. 3.1 to 3.3 respectively. From the linear graphs it can be deduced that all the points' lies on the same scatter band, in respect of their differences in the testing temperature and this can further be analyzed below in term of their slopes relationship

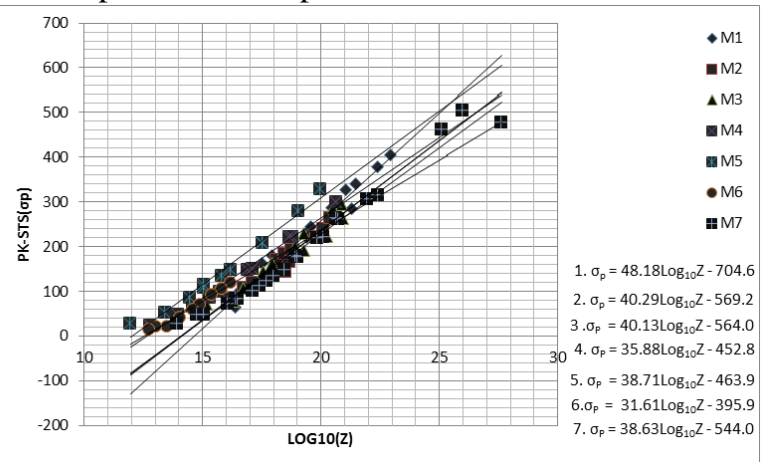

Fig 1 Dependence of the peak stress on Zener-Hollomon parameter

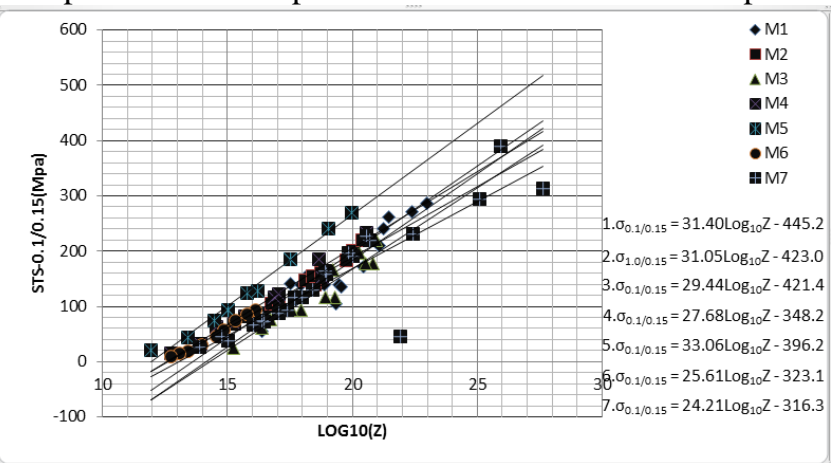

Fig 2.Dependence of stress to strain equal 0.1/0.15 on Zener-Hollomon parameter. 


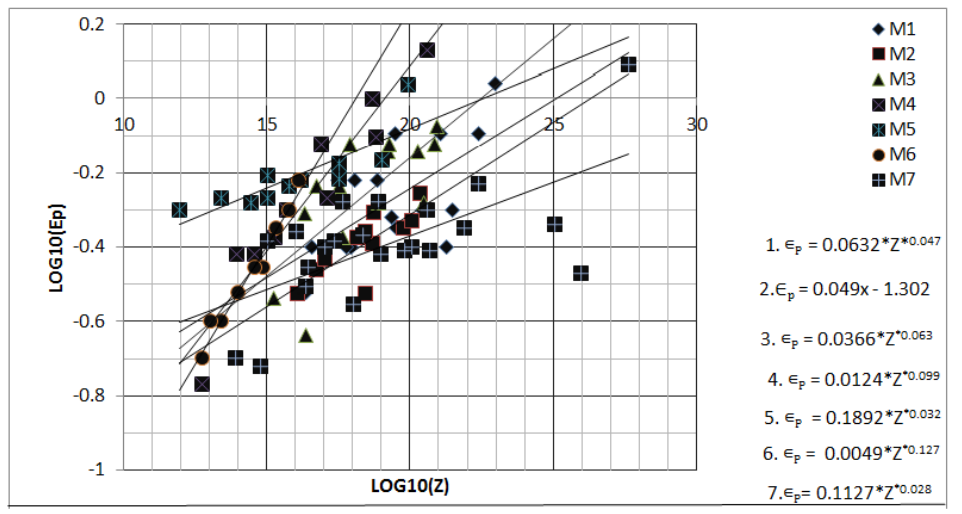

Fig 3 Dependence of maximum strain on Zener-Hollomon parameter

From the stress-strain equations analyzed in fig 1-fig 3. the stress - strain curve were obtained and the shapes for all the experimental data were discovered to have a subdivision of three different sections, a steep work hardening zone, a shallow and wide maximum stress region, and a slight transition into the steady-state part of the curve. These characteristics agree with most stress-strain curves reported for stainless steel materials.

Due to close range of the slope values of the peak stress vs. $\log _{10} \mathrm{Z}$ and stress to $0.1 / 0.15$ vs. $\log _{10} \mathrm{Z}$ as observed, these following stress-strain equations in fig 4 and fig. 5 were found to jointly describe the peak stress vs. $\log _{10} \mathrm{Z}$ and stress to $0.1 / 0.15 \mathrm{vs} . \log _{10} \mathrm{Z}$ respectively, for all the materials (M1-M7).

Since $\epsilon_{p}=k Z^{m}$

$$
\begin{gathered}
\sigma_{p}=-457.2+35.19 \log _{10} Z \ldots \ldots \ldots \\
\sigma_{0.1 / 0.15}=-296.1+23.87 \log _{10} Z
\end{gathered}
$$

Where $\mathrm{k}$ and $\mathrm{m}$ are constants whose values were found to be peculiar to each different material

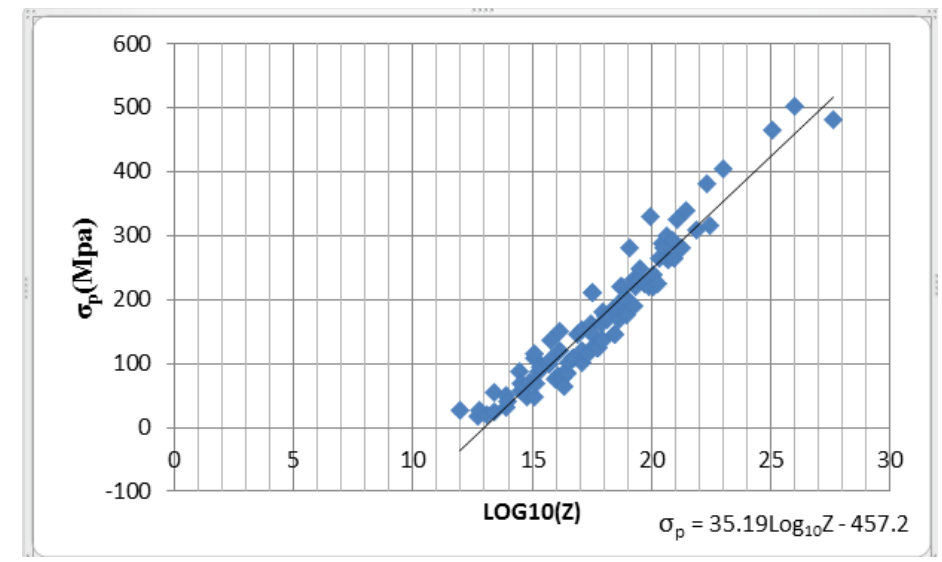

Fig 4 Dependence of the Peak Stress on the Zener-Hollomon parameter

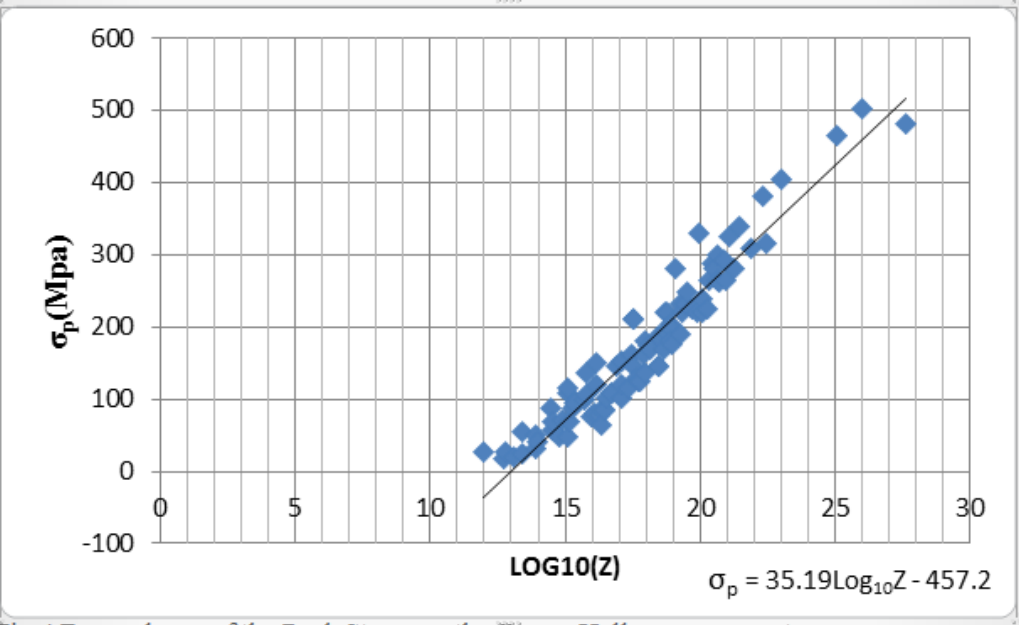

Fig 5 Dependence of the Stress to $0.1 / 0.15$ Strain on the Zener-Hollomon parameter 
With sets of equations from fig.1 to fig.3 reasonable values of Zener-Hollomon parameter (Z), the actual value of $\sigma_{p}, \sigma_{0.1} / \sigma_{0.15}$ and $\varepsilon_{p}$ were obtained. The values obtained were consequently used to calculate the yield stress and yield strength both due to load and torque with the equations (13), (15), (17) and(18) respectively.

\section{Yield strength vs. $\log _{10} \mathrm{Z}$ behaviour}

The values for yield strength due to load and torque $\left(\sigma_{g}, \sigma_{t}\right)$ against $\log _{10} Z$ are plotted. From the graphs (figures 6 and 7), it is observed that the minimum value of Zener-Hollomon parameter $(Z)$ for all the experimental data that will produce any reasonable value of yield strength due to load and torque is also within $3.16 \times 10^{12}-1 \times 10^{14}$ just as yield stress. The curve obtained can also be divided into three regions. The first one occurs when the yield strength increases with the Zener-Hollomon parameter, the second occurs when any further increase in Zener-Hollomon parameter leads to a decrease in the value of the yield strength, and the third occur when the yield strength almost remain constant with any further increase in Zener-Hollomon parameter.

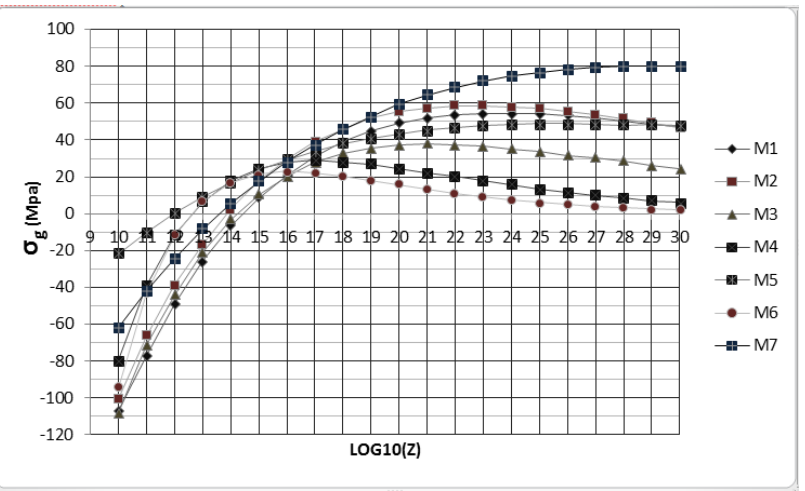

Fig. 6 Dependence of yield strength due to Load on Zener-Hollomon parameter

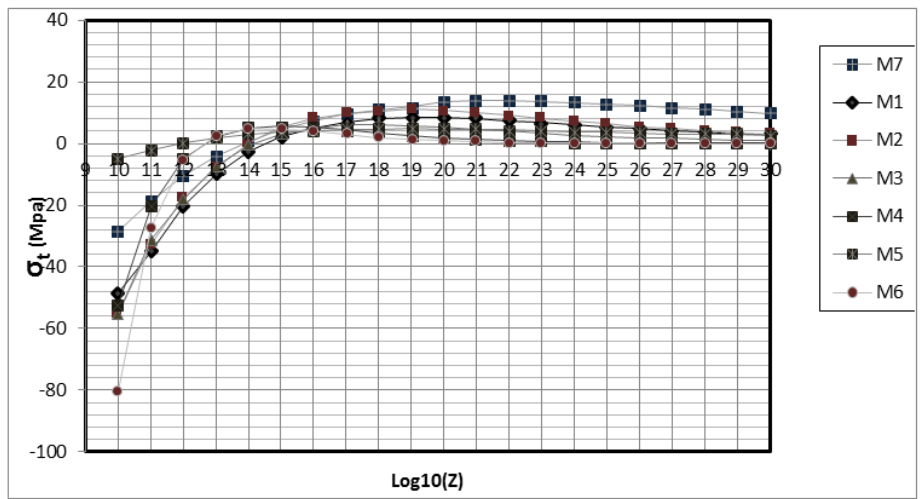

Fig. 7Dependence of yield strength due to Torque on Zener-Hollomonparameter.

\section{Yieldstrength and yield stress curve}

The calculated yield stress and yield strength due to load and torque for various experimental data for seven grade of steel were plotted against each other to their relationship as shown in fig..8 and fig. 9.

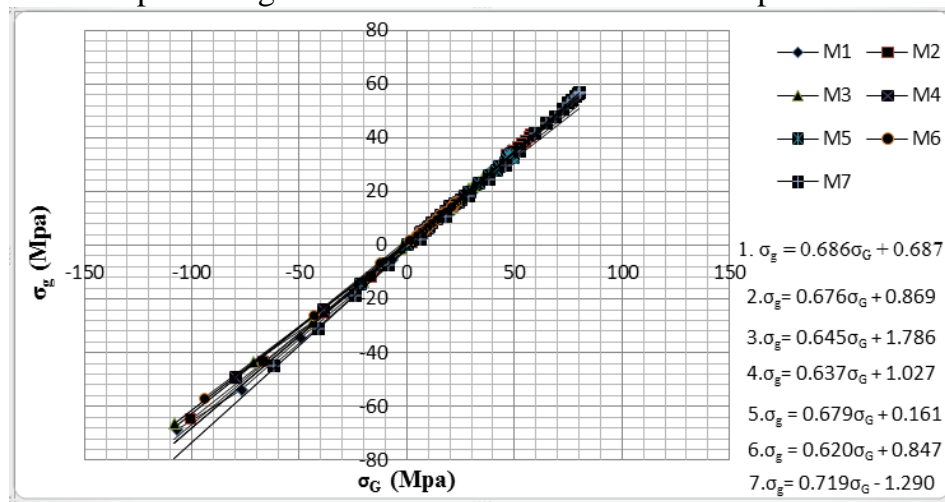

Fig 8 Dependence of yield strength on the yield stress due to load 


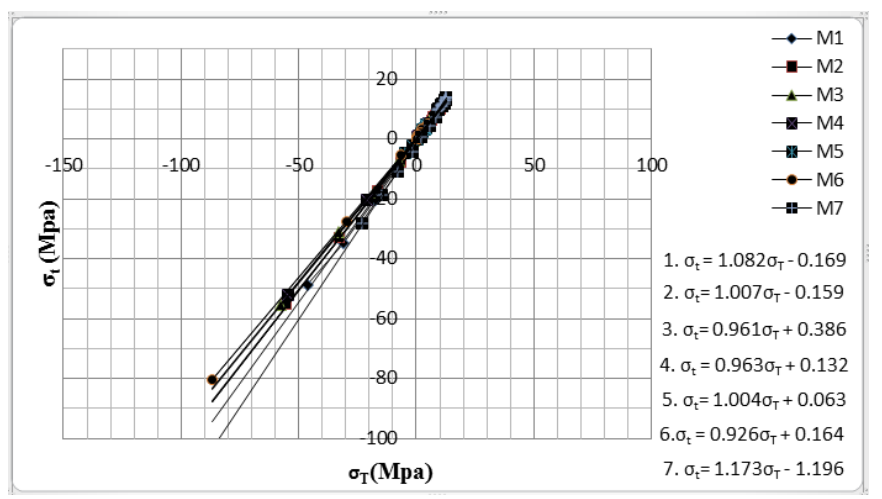

Fig 9 Dependence of yield strength on yield stress due to torque

Their slopes values are comparatively very close, between 0.63 and 0.68 (for load) and 0.9 and 1.1 (for torque).As a result of the close range in their slope values, fig. 10 and fig.11jointly describes the relationship between the yield stress and yield strength due to load and torque for all the materials (M1M7).
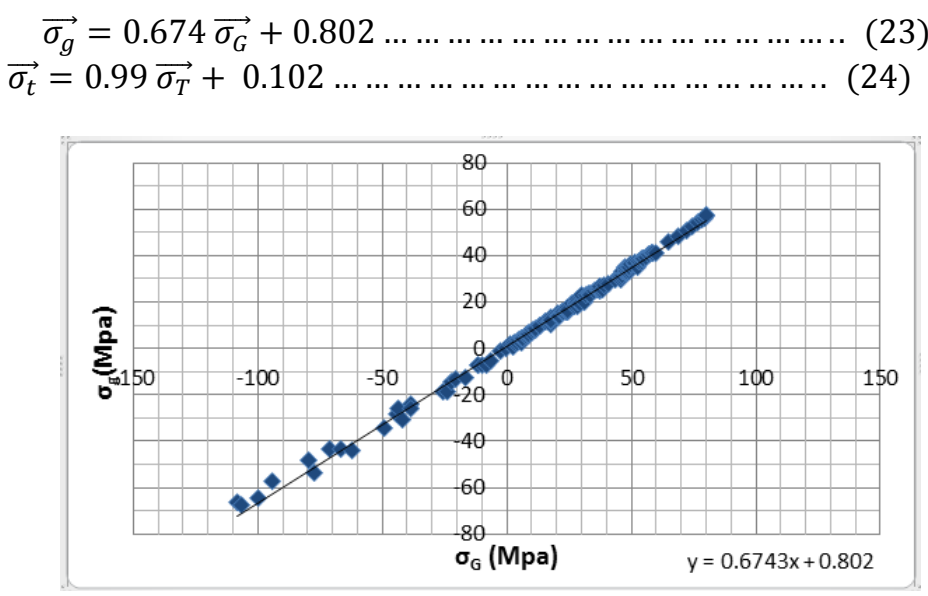

Fig 10 Dependenceof yield strength on yield stress due to Load

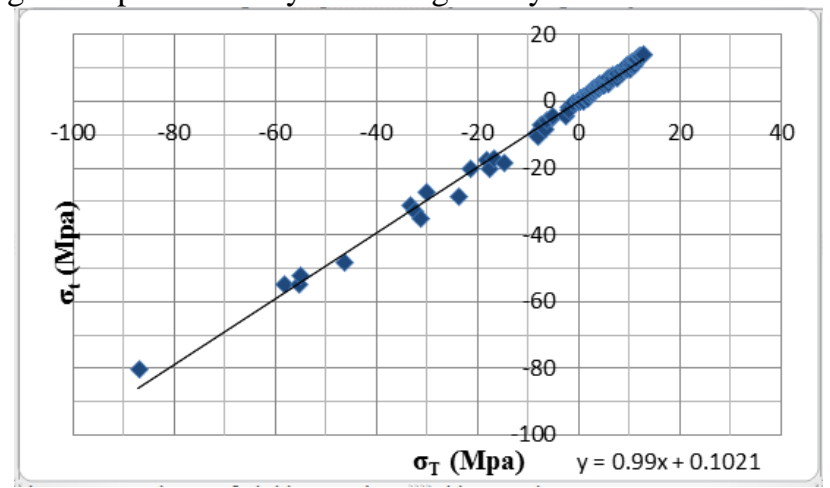

Fig 11 Dependence of yield strength on yield stress due to Torque.

\section{Conclusion}

From different torsional tests for various stainless steel materials analyzed in view of obtaining the relationship necessary or appropriate to describe the yield stress and yield strength relationship of the materials. It was observed that;

The peak stress $\left(\sigma_{p}\right)$, stress to 0.1 or $0.15\left(\sigma_{0.1 / 0.15}\right)$ and peak strain $\left(\epsilon_{p}\right)$ of various grades of stainless steels consideredwere expressed in term of Zener-Hollomon parameter as shown in equations. The stress-strain $(\sigma-\epsilon)$ curve for any value of $Z$ for the individual material can be obtained using the derived equations.

A single linear equation: $\sigma_{p}=-457.2+35.19 \log _{10} Z$ and $\sigma_{0.1 / 0.15}=-296.1+23.87 \log _{10} Z$ was obtained from the derived equations. These described the stress-strain equations of all the materials as given in equation (21) and (22). 
The graph that relate the yield strength due to load and torque to the logarithm of Zener-Hollomon parameter as shown in figures 6 and 7 gives almost similar pattern that is expected of any stress-strain curve. Studying the graphs the yield strength vs. $\log _{10} Z$ start from a specific value, this rises to peak value steadily, before decreasing to a steady state value.

Calculated yield stress and yield strength due to load and torque, for all the analyzed materials were used to obtain the equations on figure 8 and 9, which describe the relationship between yield stress and yield strength of each materials. The difference in the slope value of the equations was due to the chemical compositions of the material which were stated in Appendix 1 below.

These equations were streamlined to a single linear equation $\overrightarrow{\sigma_{g}}=0.674 \overrightarrow{\sigma_{G}}+0.802$ (for loads) and $\overrightarrow{\sigma_{t}}=0.99 \overrightarrow{\sigma_{T}}+0.102$ (for torque). These equations can be found very useful when comparing yield strength and yield stress of a stainless steel material and also in obtaining calculated rolling load and torque for such a material.

\section{References}

[1]. Aiyedun, P.O., Nwanrto, F.N.; Adeleke, A.E.; and Alamu, O.J. (2010). "Yield

[2]. Strength Estimation ForStainless Steel Using Plane Strain Compression Test". Australian Journal of Basic and AppliedSciences. 4(12), pp. 6312 - 6318. ESSN $1991-8178$.

[3]. Aiyedun, P.O., Oseghale, L.E., and Alamu, O.J. (2009), "Simulation of Load Bearing Rod Rolling ofCarbon-Manganese Steel Using the "Phantom Roll" Method," Pacific Journal of Science and Technology, Vol.10, pp 4-14.

[4]. Aiyedun, P.O. (1999), "Yield Stress Variation across thickness for Steel (HC SS316) Specimen HotRolled at low reduction and low strain rates". NSE. Technical Transactions, Vol. 34, No.1.,pp. $46-70$

[5]. Aiyedun, P.O. (1984), "A study of loads and torque for light reduction in hot flat rolling at low Strainrates," Ph.D. Thesis, University of Sheffield, UK.

[6]. Alamu, O.J. and Durowoju, M.O, (2003), "Evaluation of Zener-Hollomon parameterVariation with pass reduction in hot steel rolling." International Journal of EnvironmentalIssues, 1, pp 148-159.

[7]. Alder, J.F. and Philips, V.A. (1954-55), " The effect of strain rates and temperature in the resistance ofaluminium, copper and steel to compression.” Journal of Applied physics, Vol. 15, pp 22-32.

[8]. Barbosa, R. A. N. (1983)," Simulation of Hot working of Austenitic Stainless Steels." Ph.D. Thesis,Sheffield University.

[9]. Barraclough, D.R. and Sellars, C. M. (1975), "The effect of Varying Deformation

[10]. Conditions during Hot Tension Testing', Institute of physics conf., Vol. 21, pp 111-114

[11]. Barraclough, D.R., (1974), Ph.D. Thesis, University of Sheffield.

[12]. Colas, R.O. (1983), "High strain rates, high temperature deformation of stainless steel." Ph.D.Thesis, University of Sheffield.

[13]. Dieter, G. E. (1986), "Mechanical Metallurgy,” McGraw-Hill Book Company, New York. (Third Edition).

[14]. Dieter, G. E. (1988), "Mechanical Metallurgy”.'S.I. Metric Edition. McGraw-Hill, Inc. London

[15]. Jonas, J.J., Sellars, C.M., and Tegart, W.J. (1969), "Strength and structure under hot-workingconditions." Metallurgical reviews, 130, 1-4.

[16]. Lawal, J.B, (1999), "Yield Strength estimation for stainless steel using torsionaltest." M.Sc. Thesis,Mechanical Engineering Department, University of Ibadan.

[17]. Oyo State, Nigeria

[18]. Robert, W. and Ahlblomb, B. (1978), “Cold Rolling of steel.” Marcel Dekker Int. publishers New York ., 26, 801.

[19]. Sellars, C. M. and Tegart, W. J. (1972), “Hot workability.” International Metallurgical Reviews, No. 158, Vol. 17, pp 1-23.

[20]. Zener, C., and Hollomon, J.H. (1944), "Effect of Strain rate upon plastic flow of steel.” Journal of Applied physics, Vol. 15, pp 22-32.

Appendix 1: $\quad$ Slope Comparison

\begin{tabular}{|c|c|c|c|c|c|c|c|c|c|}
\hline \multirow[b]{2}{*}{$\begin{array}{l}\text { Material } \\
\mathrm{s}\end{array}$} & \multirow[b]{2}{*}{$\begin{array}{l}\text { Composition } \\
\text { (C/Ni/Cr/Mo) }\end{array}$} & \multirow[b]{2}{*}{$\begin{array}{l}\text { Temp. } \\
\text { Range }\left({ }^{0} \mathrm{C}\right)\end{array}$} & \multirow[b]{2}{*}{$\begin{array}{l}\text { Strain rate } \\
\left(\mathrm{s}^{-1}\right)\end{array}$} & \multirow{2}{*}{$\begin{array}{l}\text { Activation } \\
\text { Energy }(\mathrm{KJ} / \\
\text { Mole })\end{array}$} & \multicolumn{4}{|c|}{ Slopes } & \multirow[b]{2}{*}{$\sigma_{t}$ vs. $\sigma_{T}$} \\
\hline & & & & & $\begin{array}{l}\sigma_{P} \\
\text { vs } \\
\log _{10} \\
\mathrm{Z}\end{array}$ & $\begin{array}{l}\sigma_{0.1 / 0.15} \text { vs. } \\
\log _{10} Z\end{array}$ & $\begin{array}{l}\epsilon_{\mathrm{P}} \text { vs. } \\
\log _{10} \mathrm{Z}\end{array}$ & $\sigma_{g}$ vs $\sigma_{G}$ & \\
\hline M1 & $\begin{array}{l}0.07 / 10.9 / 17.2 / 2.9 \\
2\end{array}$ & $800-1000$ & $0.08-3.93$ & 460 & $\begin{array}{l}48.1 \\
8\end{array}$ & 31.40 & 0.0632 & 0.686 & 1.082 \\
\hline M2 & $\begin{array}{l}0.024 / 12.2 / 16.7 / 2 \\
63\end{array}$ & $905-1008$ & $\begin{array}{l}0.0032- \\
1.499\end{array}$ & 456 & $\begin{array}{l}40.2 \\
9\end{array}$ & 31.05 & 0.0499 & 0.676 & 1.007 \\
\hline M3 & $\begin{array}{l}0.02 / 12.4 / 16.9 / 2.7 \\
6 \\
0.55 / 12.4 / 17.4 / 2.1 \\
4\end{array}$ & $900-1200$ & $0.1-5.0$ & 455 & $\begin{array}{l}40.1 \\
3\end{array}$ & 29.44 & 0.0366 & 0.645 & 0.961 \\
\hline M4 & $0.064 / 11.4 / 18.5 /-$ & $740-1140$ & $0.001-2.5$ & 414 & $\begin{array}{l}35.8 \\
8\end{array}$ & 27.68 & 0.0124 & 0.637 & 0.963 \\
\hline M5 & $0.05 / 11.3 / 18.2 /-$ & $800-1150$ & $0.0008-1$ & 410 & $\begin{array}{l}38.7 \\
1\end{array}$ & 33.06 & 0.1892 & 0.679 & 1.004 \\
\hline M6 & $-/ 8 / 18 /-$ & 1100 & $0.001-2.5$ & 414 & $\begin{array}{l}31.6 \\
1 \\
\end{array}$ & 25.61 & 0.0049 & 0.620 & 0.926 \\
\hline M7 & $\begin{array}{l}0.054 / 11.3 / 17.40 / \\
2.5\end{array}$ & $600-1201$ & $\begin{array}{l}0.003611- \\
1.4\end{array}$ & 460 & $\begin{array}{l}38.6 \\
3\end{array}$ & 24.21 & 0.1127 & 0.719 & 1.173 \\
\hline
\end{tabular}

M1 = AISI 316L (Barbosa, 1983) M2 = AISI 316 (Colas, 1983)

M3 = AISI 316L (Barbosa, 1983)M4 = AISI 304 ( Barbosa, 1983)

M5 = AISI 304 ( Barraclough, 1974) M6 = AISI 304 (Sellars and Tegart, 1972)

M7 = HC SS316 (Aiyedun, 1984) 